\title{
The frequency of tumors of the head and neck in a 10-year period in Ilam, Iran
}

\author{
Khadijeh Abdal $^{1}$, Samira Mostafazadeh ${ }^{2}$, Marziyeh Darvishi ${ }^{3 *}$
}

1. Department of Oral and Maxillofacial Pathology, Faculty of Dentistry, Ilam University of Medical Sciences, Ilam, Iran

2. Department of Oral and Maxillofacial Pathology, Faculty of Dentistry, Urmia University of Medical Sciences, Urmia, Iran

3. Department of Anatomy, School of Medicine, Ilam University of Medical Sciences, Ilam, Iran

*Corresponding author:Tel: +98 9124205893 Fax: +98 8433331799

Address: Department of Anatomy, School of Medicine, Ilam University of Medical Sciences,

Ilam, Iran

E-mail: marzidarvish@yahoo.com

Received; 2017/11/29 revised; 2018/01/4 accepted; 2018/06/4

\section{Abstract}

Introduction: Cancer is one of the five leading causes of death around the world, and head and neck cancer is one of the most common incidences, leading to the death of thousands of people each year. Given the epidemiological importance of head and neck cancers, this study aimed to examine the prevalence of head and neck cancers over a 10-year period in Ilam.

Materials and methods: This descriptive study was done using the files of 1106 patients with head and neck lesions who were referred to Imam Khomeini hospital in Ilam in a 10year period between 2004 and 2015. All the data in the files, including age, sex, type and location of the lesion, was recorded, evaluated, and analyzed using independent t-tests and chi-square statistical methods with SPSS 19.

Results: The annual incidence of head and neck cancers in Ilam was estimated at 1.5 per 100,000 people. Basal cell carcinoma was the most common cancer of the head and neck $(18.50 \%)$. The most common site of squamous cell carcinoma occurrence was the tongue at 54\%. Regarding sex, $55.5 \%$ of patients were male and $44.5 \%$ were female. Regarding malignancy, 289 lesions (26.13\%) were reported as malignant and 817 lesions $(73.86 \%)$ were reported as benign.

Conclusion: Considering the high incidence of basal cell carcinoma and squamous cell carcinoma the importance of early diagnosis of these cancers and their treatment requires appropriate planning to improve survival of these patients and to reduce the disease's complications.

Keywords: Cancer, Basal cell carcinoma, Squamous cell carcinoma

\section{Introduction}

Two to $5 \%$ of cancers belong to head and neck cancers; almost 52,000 patients suffer from head and neck cancer, leading to the death of about 11,000 every year (1). Unfortunately, head and neck cancer has increased over the past 20 years, and in Iran over 30,000 people die due to cancer annually (2). Head and neck tumors can be benign or malignant. Benign tumors include inflammatory and congenital tumors, while malignant tumors include cancers such as lymphoma and other salivary gland tumors (3). Signs of head and neck cancer include lumps on the

Copyright (C) 2018 Journal of Basic Research in Medical Science. This is an open access article distributed under the terms of the Creative Commons Attribution 4.0 International License (https://creativecommons.org/licenses/by/4.0/) which permits copy and redistribute the material, in any medium or format, provided the original work is properly cited. 
neck, changes in voice, difficulty in swallowing, ulcerative lesions on lips and ears that do not heal, and masses inside the mouth (4). Head and neck cancers include areas of the pharynx and larynx, oral cavity, paranasal sinuses and neck squamous cells. The most common carcinoma in the neck area is squamous cell carcinoma (SCC) (5). The prevalence of oral cancers differ by age, sex, race, and geographic location (6). Oral cancers occur in men at a rate of about $4 \%$ and in women at a rate of about $2 \%$ of all cancers; in other words, the incidence of oral cancer is twice as common in men as in women (7). Research has shown that smoking is a major cause of oral cancer, and of course alcoholic drinks, constant exposure to sunlight, jobs associated with phenolic factors, genetic factors, and types of human papilloma virus (HPV) and viruses such as EBV are also causative factors (8). The prevalence of oral cancer in the United States of America is 11.3 cases per 100,000 people, and, in India, about 50\% of cancers are oral cancers. Statistical research in United States shows that about 55,000 cases of head and neck cancer are diagnosed annually, of which about 13,000 are fatal (9).Epidemiological studies of cancer examine the sex, age, social and economic differences in cancer patients in various geographic regions of the country and various countries. Such descriptive studies are applicable and useful in exploring the causes of various cancers (10).Considering that no research has been done in Ilam on the incidence of head and neck cancers and their age and sex distribution, this study aimed to examine the incidence of the head and neck cancers in a 10 -year period in Ilam.

\section{Materials and methods}

This is a descriptive - analytical study. To determine the frequency of head and neck tumors, all records of patients admitted to hospitals in Ilam during 2004 to 2015, were examined, and then records of patients with head and neck tumors were identified. Sampling method was census in this study. All the required data in the files, including age, sex, type and location of the lesion, was recorded, evaluated, and analyzed using independent t-tests and chisquare statistical methods with SPSS 19. To estimate the relative frequency of head and neck tumors, $95 \%$ confidence interval was used and the information is described with the table of frequencies.

\section{Results}

This study was done over a 10-year period (2004-2015) in Ilam. The total number of patients referred to the pathology department in Imam Khomeini hospital of Ilam was 24,559. Of these, 1,106 had head and neck lesions. $57 \%$ of the lesions were oral and $43 \%$ were head and neck lesions. Of these, $614(55.5 \%)$ were male with a mean age of $49.9 \pm 19.4$, and $492(44.5 \%)$ were female, with a mean age of $48.2 \pm$ 20.1 (Table 1). Of 1,106 diagnosed lesions in the head and neck, $289(26.1 \%)$ were malignant lesions and 817(73.9\%) were benign lesions. The youngest patient in our study was a one-year old infant with hemangioma and the oldest one was 90 years old with basal cell carcinoma (Table $1)$. Two groups of men and women were compared in terms of age using an independent $\mathrm{t}$-test and the difference was not found to be significant $(\mathrm{p}=0.15)$. This means that men and women were in the same age range. The highest frequency (34\%) was related to the age group comprising 41 to 60 years. It was also found that $25 \%$ of patients were under 62 years, and $50 \%$ were between 60 and 77 years of age. Using chi-square, the relationship between the frequency of head and neck tumors with sex and age was compared and found to be statistically significant ( $\mathrm{p}<0.001$ ). In addition, the prevalence of 35 types of head and neck tumor was recorded in this study, and the highest frequency was related to basal cell carcinoma $(18.5 \%)$. The highest head and neck cancer is basal cell carcinoma both in women (18.4\%), and in men (18.6\%). The 
highest incidence of lesions of the oral cavity (squamous cell carcinoma) was reported at $6.7 \%$, of which $54 \%$ were created in the tongue.

Table 1. Demographics of patients with types of head and neck tumors based on the age and gender.

\begin{tabular}{|c|c|c|c|c|}
\hline \multirow[t]{2}{*}{ Age (year) } & \multirow[t]{2}{*}{ Population } & \multirow[t]{2}{*}{ Prevalence } & \multicolumn{2}{|c|}{ Sex } \\
\hline & & & Male & Female \\
\hline Under 20 & 60000 & $17.1 \%$ & $46(7 / 5 \%)$ & $57(11.6 \%)$ \\
\hline $21-40$ & 80000 & $36.7 \%$ & $164(26 / 7 \%)$ & $130(26.4 \%)$ \\
\hline $41-60$ & 40000 & $26 \%$ & $213(34 / 7 \%)$ & $163(33.1 \%)$ \\
\hline $61-80$ & 20000 & $1.4 \%$ & $163(26 / 5 \%)$ & $134(27.2 \%)$ \\
\hline Up 81 & 10000 & $36 \%$ & $28(4 / 6 \%)$ & $8(1.6 \%)$ \\
\hline
\end{tabular}

\section{Discussion}

Based on the findings of this study, the annual incidence of head and neck cancers was estimated at 1.5 per 100,000 people. The annual incidence of cancer in men and women is 98 and 110 per 100,000 people, respectively (9).The findings of this study showed that the incidence of tumors of the head and neck in men was higher than in women, which was consistent with the results seen by Delavarian, Shiva, and Qbanchy (11, 12, 13).In this study, the most common age of head and neck tumors was related to the 41 to 60 age group, showing that the risk of tumors increases with aging, similar to cited references, and textbooks, and studies results $(8,14)$.The results of this study showed that the most common site of tumors in the head and neck was head and face skin, and the highest number of malignant tumors $(18.5 \%)$ was found to be basal cell carcinoma, contradicting the results seen by Qbanchy, Burket, and Silverman expressing squamous cell carcinoma the most common malignant tumor of head and neck (13, 14, 15).According to the findings of this study, basal cell carcinoma is the most common malignancy in the head and neck, which is consistent with Neville's opinion that basal cell carcinoma is the most common cancer among all cancers (8).It was reported that the highest affected area for basal cell carcinoma was the nose (43.9\%), similar to Nevliie and Burket's findings, where $80 \%$ of these lesions occurred in the head and neck. The most common complaint of patients with basal cell carcinoma was the creation of a firm nodule on the face that was similar to the results of Lyubomir's studies (16).

Other finding in this study requiring particular attention is a number of salivary gland tumors and lymphoma. While salivary gland tumors and lymphoma are expressed as cancers with high prevalence in head and neck in dental references, which may be the result of a lack of specialized centers for oral lesions and referral of patients to other health centers in surrounding towns and lack of timely referrals of patients with oral lesions (12).In terms of the incidence of oral lesions, squamous cell carcinoma $(6.7 \%$ of oral cancers was noted, which is consistent with the findings of Andishehtadbir, Qpanchy, Lei, and Castell (13, 17, 18, 19).Squamous cell carcinoma occurs more frequently in men than in women, which is inconsistent with the results of Shiva's study where the prevalence of squamous cell carcinoma was reported as higher in women (12)and is similar to studies by Picard, Dantas and Murphy that reported the incidence of squamous cell carcinoma to be higher in men than in women $(20,21$, 22).In the present study, the tongue (54\%) was the most common site, similar to results reported by Lei, Dantas and Delavaran (11, 18, 21)and contradicts Fahmi and Alrawi, who found lips the most common site of injury $(23,24)$. The most common benign lesions in the head and neck in men are pilar cysts, with $13 \%$ 
prevalence, which is similar to Neville's finding that cystic lesions occur more frequently in men than in women, $15 \%$ of the cysts occur on the scalp (8).This study's findings have shown that nevus was reported as the most common benign tumor in women (10.4\%). These results are consistent with the references and textbooks stating that nevus is the most common tumor in humans and mostly affects women and the skin of the head and neck $(8,14)$.

\section{Study limitations}

This is the first study about cancer incidence and distribution of age and sex in Ilam; however, it seems that some of the patients refer to medical centers in surrounding provinces, therefore, the estimation of the cancer incidence will be less than the actual one. Given that the treatment plans and records of referred patients was incomplete, we couldn't discuss the survival of patients in this study. Therefore, it is suggested that cancer registry system of patient records be launched prospectively.

\section{Conclusion}

The findings of this study showed that a large number of patients admitted to Imam Hospital in Ilamwere diagnosed with basal

\section{References}

1. Yuan WW1, Hang D1, Wang LH1, Chen SH, Ding ZX, Hu ZB, et al. [Association between genetic variants in microRNA biosynthesis genes and the risk of head and neck squamous cell carcinoma]. Zhonghua Liu Xing Bing Xue Za Zhi. 2016; 37(8):106973. doi: 10.3760/cma.j.issn.02546450.2016.08.003. (Article in Chinese)

2. Mousavi M, Gouya MM, Ramazani R, Davanlou M, Hajsadeghi N, Seddighi Z. Cancer incidence and mortality in iran . Annals of Oncology. 2009 cell carcinoma (the most common skin cancer) or squamous cell carcinoma (the most common oral malignancy). Considering the complications caused by the treatment of these lesions, helping people become familiar with symptoms of malignancies and promoting timely referral to health centers while doing proper planning to reduce complications caused by the disease are required. Holding continuing education training courses for doctors and dentists for their awareness and familiarity with the ways of early cancer diagnosis of the head and neck is recommended.

\section{Acknowledgements}

This study was a part of thesis and research project (Grant No: 910795) which was supported and funded by Ilam University of Medical Sciences.

\section{Conflict of interest disclosure}

The authors state that they have no conflict of interest.

\section{Author contribution}

All authors contributed to the idea, design and conduct the study and drafting the manuscript. All authors approved the final version to be submitted.
;20(3):556-63. doi:
10.1093/annonc/mdn642.

3. Sink J, Kademani D. Maxillofacial oncology at the University of Minnesota: treating the epidemic of oral cancer. Northwest Dent. 2011;90(3):13-6, 38.

4. Bassey G, Osunde O, Anyanechi C. Maxillofacial tumors and tumor-like lesions in a Nigerian teaching hospital: an eleven year retrospective analysis. Afr Health Sci. 2014;14(1):56-63. doi: 10.4314/ahs.v14i1.9. 
5. Abdal K, Salehinejad J, Mostafazadeh S. Evaluatingthe frequency of clinical and microscopic views of Basal Cell Carcinoma in a10-year period. $\mathrm{J}$ Res Dentomaxillofac Sci.2016;1(4):39-45.

6. Brouwer AF, Eisenberg MC, Meza R. Age effects and temporal trends in HPV-related and HPV-unrelated oral cancer in the United States: A multistage carcinogenesis modeling analysis. PLoS One. 2016 ;11(3):7881. doi: 10.1371/journal.pone.0151098.

7. Marur S, Forastiere AA. head and neck squamous cell carcinoma: update on epidemiology, diagnosis, and treatment. Mayo Clin Proc. 2016 ;91(3):386-96. doi: 10.1016/j.mayocp.2015.12.017.

8. Khiavi MM, Abdal K, Abbasi MM, Hamishehkar H, Aghbali AA, Salehi $\mathrm{R}$, et al. Comparison of injectable doxorubicin and its nanodrug complex chemotherapy for the treatment of 4nitroquinoline-1-oxide induced oral squamous cell carcinoma in rats. Indian J Med Res. 2017;145:112-7. doi: 10.4103/ijmr.IJMR_542_14.

9. Petersen PE. The world oral health report 2003: Continues improvement of oral health in the 21 st century the approach of the WHO Global Oral Health program. Community Dent Oral Epidemiol. 2003;31(1):3-23.

10. Gooi Z, Chan JY, Fakhry C. The epidemiology of the human papillomavirus related to oropharyngeal head and neck cancer. Laryngoscope. 2016 ;126(4):65-9. doi: 10.1002/lary.25767.

11. Delavarian Z, Pakfetrat A, Mahmoudi SM. [Five years retrospective study of oral and maxillofacial malignancies in patient referred to oral medicin department of Mashhad dental school Iran]. J Mashhad Dent School. 2009;33(2): 129-38. (Article in Persian)

12. Shiva A, Mousavi S. [Epidemiologic study of oral and paraoral malignancies in sari, iran]. J Mashhad Dent School. 2014;38 (4):337-46. (Article in Persian)

13. Ghapanchi J, Mortazavi M, Parhiz H. Analytic evaluation of the prevalence of head and neck cancers among patient with different kinds of cancers visited in radiotherapy department of namazi hospital , 2003-2004. J Dentistry Shiraz Uni Med Sci. 2004;5(1-2):97-105. (Article in Persian) doi: 10.1186/s13104-0151773-9.

14. Burket's in Oral Medicin. Michael Glick. People's Medical Publishing House - USA, Ltd.; 12 edition (December 26, 2014).

15. Silverman S Jr, Sugerman PB. Oral premalignancies and squamous cell carcinoma. Clin Dermatol. 2000;18(5):563-8.

16. Abdal K, Salehinejad J, Mostafazadeh S. Evaluatingthe frequency of clinical and microscopic views of Basal Cell Carcinoma in a10-year period. J Res Dentomaxillofac Sci.2016;1(4):39-45.

17. Castellsagué X, Alemany L, Quer M, Halec G, Quirós B, Tous S, et al. HPV involvement in head and neck cancers: comprehensive assessment of biomarkers in 3680 patients. J Natl Cancer Inst. 2016 28;108(6):djv403. doi: 10.1093/jnci/djv403.

18. Lei F, Chen JY, Wang WC. Retrospective study of oral and maxillofacial lesions in older Taiwanese patients. Gerodontology. 2015;32(4):281-7. doi: 10.1111/ger.12118.

19. Andishetadbir A, Mehrabani D, Heydari S. Primery malignant tumors of orofacial origin in iran . Craniofac Surg. 2008;19(6):1538-41. doi: 10.1097/SCS.0b013e31818eeccb.

20. Picard A, Badoual C, Hourseau M. Human papilloma virus prevalence in HIV patients with head and neck squamous cell carcinoma. AIDS. 2016 ;30(8):1257-66. doi: 10.1097/QAD.0000000000001030. 
21. Dantas TS, de Barros Silva PG. Influence of Educational Level, Stage, and Histological Type on Survival of Oral Cancer in a Brazilian Population: A Retrospective Study of 10 Years Observation. Medicine (Baltimore). $2016 \quad$;95(3):79-84. doi: 10.1097/MD.0000000000002314.

22. Murphy J, Berman DR, Edwards SP, Prisciandaro J, Eisbruch A, Ward BB. Squamous Cell Carcinoma of the Tongue During Pregnancy: A Case Report and Review of the Literature. J Oral Maxillofac Surg.
2016;74(12):2557-66. doi: 10.1016/j.joms.2016.06.173.

23. Alrawi N, Talabani N. Squamous cell carcinoma of the oral cavity : Acase series analysis of clinical presentation and histological grading of 1425 cases from Iraq. Clin Oral Invest. 2008;12(1):15-8.

DOI:10.1007/s00784-007-0141-0.

24. Fahmi M, Sadeghi A, Behmard S. Epidemiologic study of oral cancer in Fars province, Iran. Community Dent Oral Epidemiol.1983;11(1):50-8. 